Article

\title{
Fully Printed Zinc Oxide Electrolyte-Gated Transistors on Paper
}

\author{
José Tiago Carvalho ${ }^{1}{ }^{\mathbb{D}}$, Viorel Dubceac ${ }^{1}{ }^{\mathbb{D}}$, Paul Grey ${ }^{1}$, Inês Cunha ${ }^{1}$, Elvira Fortunato ${ }^{1}$, \\ Rodrigo Martins ${ }^{1}$, Andre Clausner ${ }^{2}$, Ehrenfried Zschech ${ }^{2}$ and Luís Pereira ${ }^{1, *}$ \\ 1 CENIMAT/I3N, Departamento de Ciência dos Materiais, Faculdade de Ciências e Tecnologia, FCT, \\ Universidade Nova de Lisboa and CEMOP-UNINOVA, Campus da Caparica, 2829-516 Caparica, Portugal; \\ jt.carvalho@campus.fct.unl.pt (J.T.C.); v.dubceac@campus.fct.unl.pt (V.D.); paul16_grey@yahoo.de (P.G.); \\ i.cunha@campus.fct.unl.pt (I.C.); emf@fct.unl.pt (E.F.); rfpm@fct.unl.pt (R.M.) \\ 2 Fraunhofer Institute for Ceramic Technologies and Systems (IKTS), 01109 Dresden, Germany; \\ andre.clausner@ikts.fraunhofer.de (A.C.); ehrenfried.zschech@ikts.fraunhofer.de (E.Z.) \\ * Correspondence: lmnp@fct.unl.pt
}

Received: 28 December 2018; Accepted: 22 January 2019; Published: 30 January 2019

check for updates

\begin{abstract}
Fully printed and flexible inorganic electrolyte gated transistors (EGTs) on paper with a channel layer based on an interconnected zinc oxide $(\mathrm{ZnO})$ nanoparticle matrix are reported in this work. The required rheological properties and good layer formation after printing are obtained using an eco-friendly binder such as ethyl cellulose (EC) to disperse the $\mathrm{ZnO}$ nanoparticles. Fully printed devices on glass substrates using a composite solid polymer electrolyte as gate dielectric exhibit saturation mobility above $5 \mathrm{~cm}^{2} \mathrm{~V}^{-1} \mathrm{~s}^{-1}$ after annealing at $350{ }^{\circ} \mathrm{C}$. Proper optimization of the nanoparticle content in the ink allows for the formation of a $\mathrm{ZnO}$ channel layer at a maximum annealing temperature of $150^{\circ} \mathrm{C}$, compatible with paper substrates. These devices show low operation voltages, with a subthreshold slope of $0.21 \mathrm{~V} \mathrm{dec}^{-1}$, a turn on voltage of $1.90 \mathrm{~V}$, a saturation mobility of $0.07 \mathrm{~cm}^{2} \mathrm{~V}^{-1} \mathrm{~s}^{-1}$ and an $\mathrm{I}_{\mathrm{on}} / \mathrm{I}_{\text {off }}$ ratio of more than three orders of magnitude.
\end{abstract}

Keywords: zinc oxide; nanoparticles; paper transistors; printed electronics; electrolyte-gated transistors

\section{Introduction}

Printed electronics (PE) has attracted strong interest among researchers aiming to introduce simpler fabrication techniques for low cost consumer electronics. PE uses well established processes, such as flexo, screen, rotary-screen, inkjet, and off-set printing, and the use of lithography and subtractive etching steps is avoided [1]. These processes offer unique large area processing capability and high throughput on flexible substrates by roll-to-roll (R2R) processes, and it opens a path toward ultra-cost-effective, flexible, and environmentally friendly electronic devices, demanded by modern society standards.

Electrolyte-gated transistors (EGTs) have attracted great interest for flexible electronics and biosensing applications over the last decade [2]. In EGTs, an electrolyte is used as a gate dielectric between the gate electrode and the channel layer. Thus, applying a voltage to the gate electrode causes ion migration in the electrolyte, leading to the formation of an electric double layer (EDL) at the electrolyte/channel interface. This results in large gate capacitance (virtually independent of the thickness) in the order of $1-10 \mu \mathrm{F} \mathrm{cm}{ }^{-2}$, enabling charge accumulation into the semiconductor at low gate voltages [3]. This makes EGTs very attractive for PE, where thin insulating dielectric layers capable of providing high gate capacitance are difficult to obtain by printing techniques at temperatures compatible with paper substrates [4-7]. Moreover, EGTs are highly sensitive to the ionic species that may contact or exist in the electrolyte. Due to their low operation voltages $(<2 \mathrm{~V})$ EGTs are 
highly desirable for biosensing applications, i.e., to determine and to quantify biological molecules inside aqueous media [8-10].

Solution-processed inorganic semiconductors used in printed EGTs have advantages over organic ones, such as higher intrinsic carrier mobility and stability [11,12]. However, in comparison to organic alternatives, high temperatures are needed to convert the precursors and to synthesize inorganic semiconductors from solution as well as to remove binders or stabilizers from the printed semiconductor ink [13]. These so-called burn-out temperatures could compromise their application on paper substrates. In this context, oxide semiconductor nanoparticle (NP)-based layers are an alternative, avoiding the need of high temperature and long or complex annealing processes to convert a precursor and to form a semiconducting layer.

This study reports the development of fully printed EGTs, based on an interconnected $\mathrm{ZnO}$ nanoparticle matrix, arranged in a staggered-top gate architecture. Ethyl cellulose (EC), a cellulose derivative, has been proven to be an indispensable binder in the developed inks, providing the necessary rheological properties for screen printing. Additionally, this eco-friendly biopolymer provides excellent printability and leveling [14] combined with excellent adhesion to paper substrates. Proper formulation of the $\mathrm{ZnO}$ printable ink allows one to process these devices at temperatures below $150{ }^{\circ} \mathrm{C}$, totally compatible with paper substrates.

\section{Materials and Methods}

$\mathrm{ZnO}$ ink formulation for screen-printing: The semiconductor ink consists of a dispersion of $\mathrm{ZnO}$ NPs in a cellulose derivative, the ethyl cellulose (EC). ZnO nanopowder (Sigma-Aldrich, St. Louis, MO, USA, $<100 \mathrm{~nm}$ particle size) was dispersed with different concentrations (10 $\mathrm{wt} \% \mathrm{ZnO} 10$ and $40 \mathrm{wt} \%$ $\mathrm{ZnO} 40$ ) into a solution of $5 \mathrm{wt} \%$ EC (Sigma-Aldrich, St. Louis, MO, USA), viscosity $300 \mathrm{cP}$, extent of labeling: $48 \%$ ethoxyl) in a solvent mixture of toluene/ethanol $(80: 20 \mathrm{v} / \mathrm{v})$ supplied from Merck (Darmstadt, Germany), $\geq 99 \%$ and Fisher Scientific (Pittsburgh, PA, USA), respectively. The resultant mixture was stirred for $12 \mathrm{~h}$ to obtain a well dispersed and homogeneous white viscous solution. Finally, the prepared inks were stored in a refrigerator at $3{ }^{\circ} \mathrm{C}$, due to the high volatility of the components, until use.

Composite solid polymer electrolyte (CSPE) ink formulation for screen-printing: The lithium-based polymer electrolyte ink is composed of a mixture of succinonitrile (Aldrich, St. Louis, MO, USA), an acrylic thermoplastic resin (TB $3003 \mathrm{~K}$, ThreeBond, Saint-Ouen-1'Aumône, France), a lithium salt ( $\mathrm{LiClO}_{4}$, Sigma-Aldrich), and titanium dioxide NPs ( $\mathrm{TiO}_{2}$, Rockwood Pigments NA, Inc., Beltsville, MD, USA). All proceeding steps were carried out at $60^{\circ} \mathrm{C}$ and relative humidity of $50 \%$.

Electrolyte-gated transistor fabrication and characterization: The fully printed ZnO NP EGTs were produced with a staggered-top gate structure onto glass (Marienfeld) and paper substrates, by a custom-made screen-printing. All materials were used without any further purification. Carbon interdigital source/drain (S/D) electrodes (effective $\mathrm{W} / \mathrm{L}=39725 \mu \mathrm{m} / 330 \mu \mathrm{m} \approx 120$ ) were printed by a polyester mesh model 120-34, using a carbon paste (TU-10s, Asahi Chemical Research Laboratory Co., Ltd., Utsuki-cho, Hachioji, Tokyo) dried at $150{ }^{\circ} \mathrm{C}$ for $30 \mathrm{~min}$ in air. An average thickness of $5.46 \pm 0.51 \mu \mathrm{m}$, through a single printing step, was achieved. For the channel layer, $\mathrm{ZnO} 10$ and $\mathrm{ZnO} 40$ inks were printed through a mesh model 77-55 with a single printing step, achieving an average thickness of $1.39 \pm 0.14 \mu \mathrm{m}$ and $4.60 \pm 0.72 \mu \mathrm{m}$, respectively. The same mesh was used to print the CSPE layer (average thickness of $18.43 \pm 1.23 \mu \mathrm{m}$ ), which was cured at $70{ }^{\circ} \mathrm{C}$ for $5 \mathrm{~min}$, followed by UV-exposure for $5 \mathrm{~min}$. Lastly, the silver gate electrode was printed via a 120-34 mesh (average thickness of $1.78 \pm 0.60 \mu \mathrm{m}$ ). For that, silver ink (PE-AG-530, from Conductive Compounds, Inc., Hudson, NH, USA) was printed and dried at $70{ }^{\circ} \mathrm{C}$ for $5 \mathrm{~min}$, in air.

Prior to printing steps, glass substrates were cleaned in an ultrasonic bath for $5 \mathrm{~min}$, first in acetone and then in isopropanol, after that rinsed off in deionized water (Millipore) and then dried using nitrogen. Regarding the paper substrates, regular printing paper and nanocellulose paper was based on microfibrillated cellulose (referred to as MFC Kraft). MFC Kraft was produced from a Kraft pulp 
subjected to a mechanical treatment followed by six homogenizing steps at 1500 bar. The nanocellulose paper was prepared by slow casting and evaporation of water from $20 \mathrm{~mL}$ of MFC suspension ( $2 \mathrm{wt} \%$ MFC) under ambient conditions in polystyrene Petri dishes (85 $\mathrm{mm}$ diameter). The resulting paper substrates had a thickness of approximately $62.4 \mu \mathrm{m}$, estimated from the average of five measurements made using a Mitutoyo digital micrometer.

The thickness of the screen-printed layers was measured with an Ambios XP-Plus 200 Stylus profilometer. The channel length $(\mathrm{L})$ and width $(\mathrm{W})$ of the EGTs were measured using a Leica IC80 HD microscope and LAS V4.3 software. The EGTs were electrically analyzed in the dark at room temperature using a microprobe station (M150 Cascade Microtech, Beaverton, OR, USA) connected to a semiconductor parameter analyzer (4155C Agilent, Santa Clara, CA, USA) controlled by the software Metrics ICS.

Nanoindentation experiments were performed using a Hysitron TI 950 Triboindenter tool with a Berkovich indenter on three different sample regions, with the goal to characterize the films mechanically. For each region, the indents were performed with a maximum load, $\mathrm{P}_{\max }$, of $1000 \mu \mathrm{N}, 2500 \mu \mathrm{N}$, and $5000 \mu \mathrm{N}$. For each $\mathrm{P}_{\max }, 20$ indents were made, with a $5 \mathrm{~s}$ loading time, a $10 \mathrm{~s}$ creep time, and finally a 5 s unloading time.

\section{Results and Discussion}

Figure 1a depicts the process steps of the fully printed EGTs arranged in a staggered-top gate architecture. Figure 1b,d show the topographical SEM surface image of screen-printed layers on glass starting from ZnO inks with different NPs content (for details regarding ink formulation, please see "Materials and Methods" section). The morphology is similar, despite the visible agglomerates for the lowest $\mathrm{ZnO}$ content (Figure 1c,e). The RMS surface roughness values obtained by AFM (Figure S1) are $115.1 \mathrm{~nm}$ and $132.8 \mathrm{~nm}$ for layers printed from $\mathrm{ZnO} 10$ (10 wt \% ZnO NPs) and ZnO40 (40 wt \% ZnO NPs) inks, respectively. It is known that high surface roughness can heavily influence the interface quality, compromising the device performance [15]. Nonetheless, the rheologic characteristics of the ink developed here provided a good packing and self-leveling of the NPs, resulting in excellent film compactness and substrate coverage, ensuring continuous conduction paths, as required for fully functional devices.

Since the target is to fabricate EGTs on paper substrates, the mechanical properties of individual $\mathrm{ZnO} 40$ screen-printed films were studied after being submitted to bending cycles. Figure S2 shows that the electrical resistance of the screen-printed $\mathrm{ZnO} 40$ films on paper continuously increases after 100 , 500, and 1000 bending cycles. Crack formation (see Figure S3) observed after 1000 bending cycles helps to explain this. Nanoindentation was performed in three different regions of the $\mathrm{ZnO}$ screen-printed layers subjected to the 1000 bending cycles to determine Young's modulus (E) and the indentation hardness $(\mathrm{H})$ (see Figure S4). For the analysis, the maximum penetration depth $\left(\mathrm{h}_{\mathrm{c}}\right)$, was set around $2 \mu \mathrm{m}$, i.e., less than $10 \%$ of the thickness of the layer, to avoid effects of the paper substrate [16]. Both $\mathrm{E}$ and $\mathrm{H}$ decrease with increased $h_{c}$, which is related with the fluence of the non-sintered ZnO NPs during the indentation. The non-ideal cohesion between them also explains why the $\mathrm{E}$ and $\mathrm{H}$ are consistently lower after bending cycles.

The ionic and electrochemical response of the CSPE used in this work was determined using electrochemical impedance spectroscopy (EIS). For further details about CSPE characterization please see Figure S5. Figure 2a,b show the experimental data and the fitting obtained from the equivalent circuit model (ECM) for both Bode and Nyquist plots. EDL formation (stabilizing effective capacitance, $\mathrm{C}_{\mathrm{eff}}$ ) occurs for frequencies below $25 \mathrm{~Hz}$, determining the transition from the resistive to the capacitive regime (phase angle equal to $-45^{\circ}$ ). This is normally also a good indicator about the cut-off frequency [17], which is usually a limitation of the EGTs, namely those using solid-state electrolytes. 

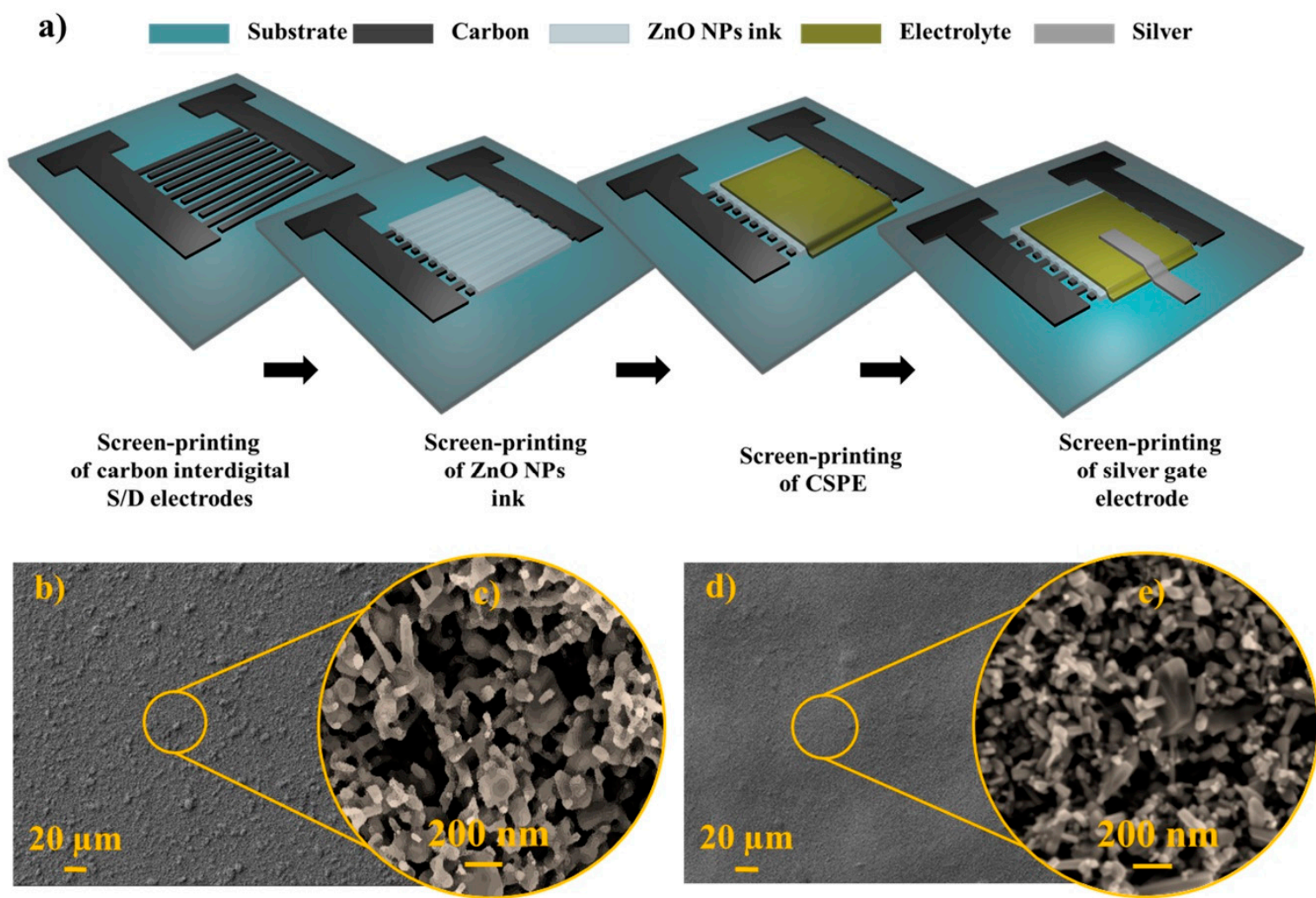

Figure 1. (a) Schematic representation of the fabrication steps for the fully printed ZnO electrolytegated transistors (EGTs). (b,c) Topographical view of the screen-printed layer using ZnO10 ink. (d,e) Topographical view of the screen-printed layer using $\mathrm{ZnO} 40$ ink.
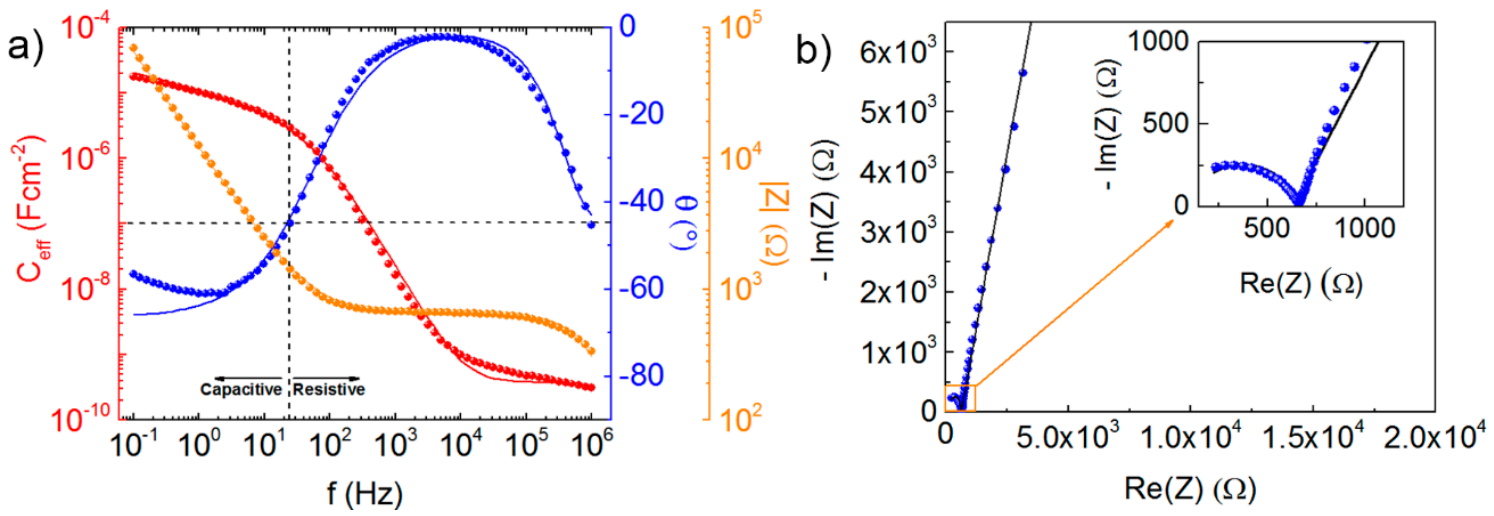

Figure 2. (a) The measured effective capacitance, phase, and impedance variation with frequency and (b) the respective Nyquist plot of the composite solid polymer electrolyte (CSPE).

$\mathrm{C}_{\text {eff }}$ gradually stabilizes at a value of about $20 \mu \mathrm{F} \mathrm{cm}{ }^{-2}$ for low frequencies. Some authors use this value as the $C_{D L}$ for further calculations, which is a conservative approach if it is not possible to fit the impedance data with the model, leading to underestimated mobility values, for instance. However, it does not consider contact resistances or the surface inhomogeneities, leading to erroneous values. Here we use Equation (1), proposed by Jovic et al. [18].

$$
\mathrm{C}_{\mathrm{DL}}=\left[\mathrm{Y}_{0} \mathrm{R}_{\mathrm{ext}}^{-(\alpha-1)}\right]^{1 / \alpha}
$$

where $Y_{0}$ is linked to the capacitance of the $\mathrm{CPE}$, and $\alpha$ is a constant (between 0 and 1 ), often referred to as the fractal surface character of the interface, denoting how non-ideally the CPE behaves. The value of 
$\mathrm{C}_{\mathrm{DL}}$ was determined at $2.47 \mu \mathrm{F} \mathrm{cm} \mathrm{cm}^{-2}$. It is important to note that countless factors are involved, such as the cell setup and dimensions, or even the ECM fitting parameters, which also have an associated error. Nevertheless, the determined values are in the typical range for the use of solid electrolytes in EGTs, i.e., $1-10 \mu \mathrm{F} \mathrm{cm}^{-2}$, as described by Kim et al. [2].

The transfer characteristics (drain-source current $\left(\mathrm{I}_{\mathrm{DS}}\right)$ vs. gate-source voltage $\left(\mathrm{V}_{\mathrm{GS}}\right)$ ) of the fully printed ZnO NP EGTs on glass and on paper substrates are shown in Figure 3a,c, respectively. Apart from the $\mathrm{ZnO}$ concentration in the ink (10 and $40 \mathrm{wt} \%$ ) and the substrate used, the device characterization was focused on the influence of the post-printing annealing temperature of the semiconducting inks. The consequent removal of the binder (EC) would ultimately lead to the desired electrical properties, given by the ZnO NPs. As evidenced by TG-DSC (see Figures S6 and S7), temperatures above $350{ }^{\circ} \mathrm{C}$ are high enough to fully degrade the binder. Taking this temperature into account, Figure $3 a$ depicts the $\mathrm{I}_{\mathrm{DS}}-\mathrm{V}_{\mathrm{GS}}$ transfer characteristic for the $\mathrm{ZnO} 10_{350}{ }^{\circ} \mathrm{C}$ Glass $\mathrm{EGT}$. These devices printed on glass substrates show n-type and normally off behavior. Once in the on-state, they reach an $\mathrm{I}_{\mathrm{DS}}$ value in the range of $10 \mu \mathrm{A}$, with an on/off current $\left(\mathrm{I}_{\mathrm{on}} / \mathrm{I}_{\text {off }}\right)$ ratio of three orders of magnitude, owing to the intrinsic high double layer capacitance of the CSPE [19]. On the other hand, no modulation was observed if the annealing temperature decreases below $350{ }^{\circ} \mathrm{C}$.
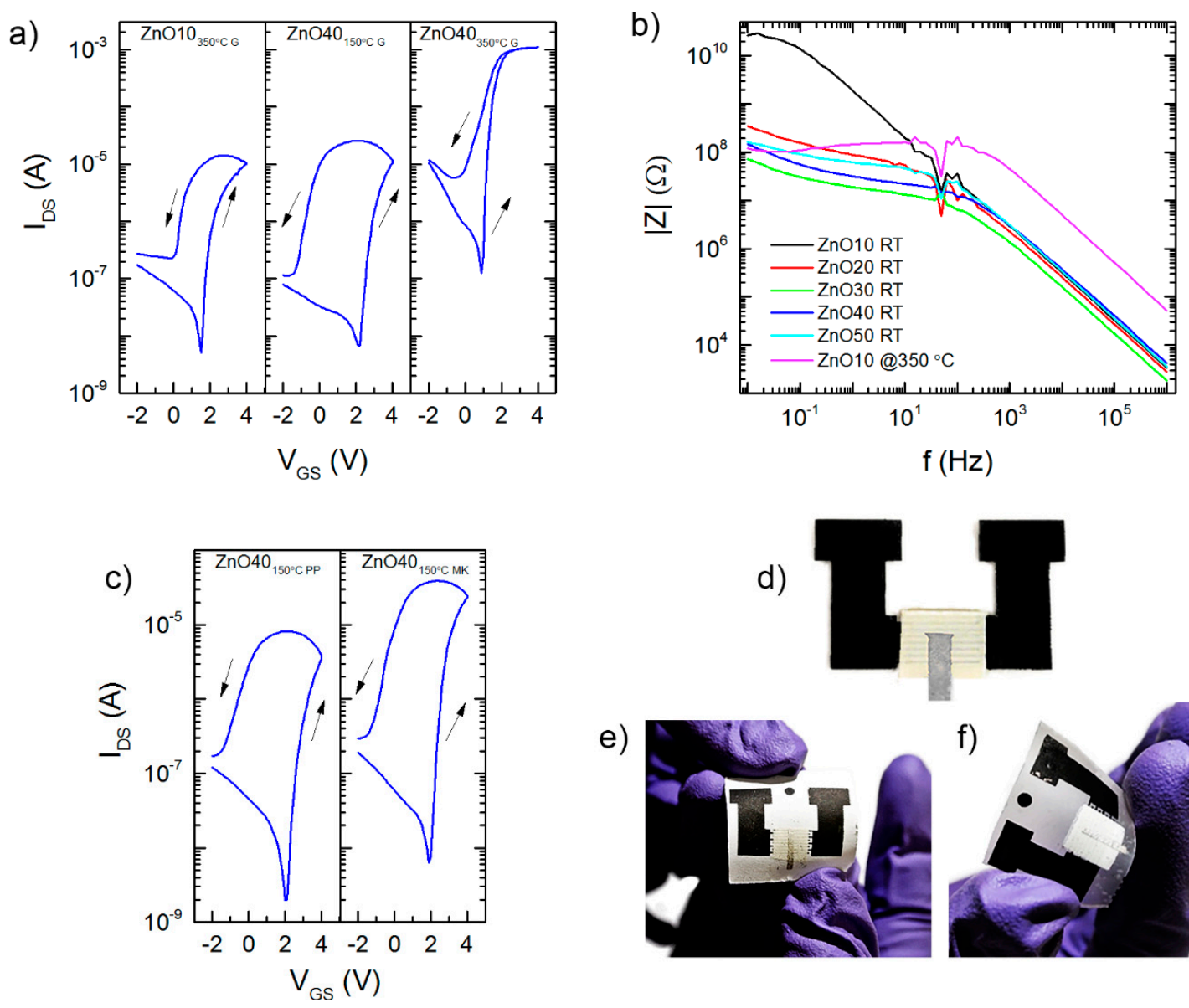

d)

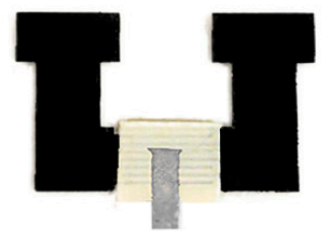

e)

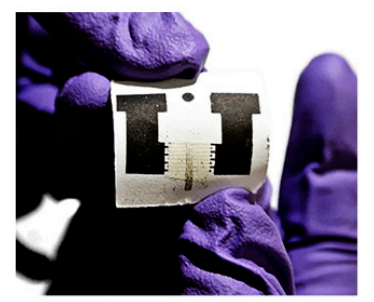

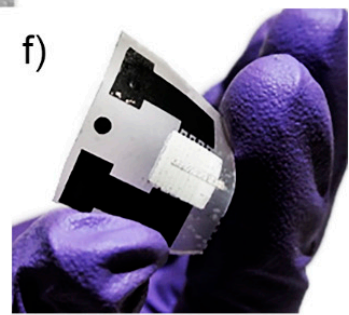

Figure 3. (a) Representative transfer characteristics ( $\left.\mathrm{I}_{\mathrm{DS}}-\mathrm{V}_{\mathrm{GS}}\right)$ of the ZnO NP EGTs on glass, namely $\mathrm{ZnO10}$ EGT annealed at $350^{\circ} \mathrm{C}\left(\mathrm{ZnO}_{3}{ }_{350}{ }^{\circ} \mathrm{C}\right.$ Glass (G) $)$; the $\mathrm{ZnO} 40$ EGT under processing temperatures of $150{ }^{\circ} \mathrm{C}\left(\mathrm{ZnO} 0_{150}{ }^{\circ} \mathrm{CG}\right)$ and the $\mathrm{ZnO} 40$ EGT annealed at $350{ }^{\circ} \mathrm{C}\left(\mathrm{ZnO}_{3} 0_{350}{ }^{\circ} \mathrm{CG}\right)$, respectively. (b) Impedance $|Z|$ of the developed $\mathrm{ZnO} N$ Ps inks, i.e., ZnO10, -20, -30, -40 , and -50 measured without annealing (RT), and for the $\mathrm{ZnO10}$ ink after annealing at $350^{\circ} \mathrm{C}$. (c) The $\mathrm{I}_{\mathrm{DS}}-\mathrm{V}_{\mathrm{GS}}$ of the $\mathrm{ZnO} 40$ EGT on printing paper $\left(\mathrm{ZnO} 40_{150}{ }^{\circ} \mathrm{CPP}\right)$ and the $\mathrm{ZnO} 40$ EGT on MFC Kraft $\left(\mathrm{ZnO}^{\circ} 0_{150}{ }^{\circ} \mathrm{C}\right.$ MK $)$, both at processing temperatures of $150^{\circ} \mathrm{C}$. An image of the printed EGTs on (d) glass, (e) printing paper, and (f) MFC Kraft. 
Aiming to reduce the annealing temperature, the $\mathrm{ZnO}$ nanoparticle concentration in the ink was increased up to $40 \mathrm{wt} \%$. As depicted on Figure 3a, proper optimization of the NP content allows for electrical modulation at annealing temperatures of only $150{ }^{\circ} \mathrm{C}\left(\mathrm{ZnO} 40150^{\circ} \mathrm{C}\right.$ Glass $)$. Higher NP content in the ink promotes more conductive paths between the S/D electrodes, without compromising the printability and layer formation. It is worth mentioning here the advantage of using screen-printing since it enables one to print in a wide range of viscosities, allowing the increase in the ZnO NPs content in the ink. Doing so, the resulting printed $\mathrm{ZnO}$ layer have lower impedance $|\mathrm{Z}|$, as shown in Figure 3b, suitable for use as a channel in EGTs. Thus, by increasing the ZnO NP concentration, the impedance measured for printed patterns using the $\mathrm{ZnO} 40$ ink without annealing, is similar to the one measured when using $\mathrm{ZnO} 10$ ink after annealing at $350{ }^{\circ} \mathrm{C}$. Consequently, the performance of EGTs based on $\mathrm{ZnO} 40$ ink annealed at $150{ }^{\circ} \mathrm{C}$ is similar to that obtained for devices using the $\mathrm{ZnO} 10$ ink annealed at $350{ }^{\circ} \mathrm{C}$, with an on/off ratio in the same order of magnitude, a saturation mobility $\left(\mu_{\text {Sat }}\right)$ of $0.02 \mathrm{~cm}^{2}(\mathrm{Vs})^{-1}$, but a higher anti-clockwise hysteresis. The saturation mobility $\left(\mu_{\text {Sat }}\right)$ was determined using Equation (S1), as described in the Supporting Information.

It can be inferred that, without eliminating totally the EC binder, it may behave as an extension of the electrolyte into the semiconducting layer. Previous studies have shown that cellulose can have electrolyte-like behavior in paper transistors [20-24]. Thus, if the EC is not totally eliminated and remains in the printed layer, electrolytic behavior is extended to the $\mathrm{ZnO} N P$ channel. The $\mathrm{ZnO}$ matrix stays intact as the current modulation is observed. However, ions can penetrate or be trapped in the EC matrix and remain in the vicinity of the semiconductor NPs, even when sweeping back to negative $\mathrm{V}_{\mathrm{GS}}$, resulting in ion trapping. The hypothesis of electrolyte extension is sufficiently supported by the results obtained for the EGT based on $\mathrm{ZnO} 40$ ink annealed at $350{ }^{\circ} \mathrm{C}$ printed on glass $\left(\mathrm{ZnO} 40_{350^{\circ}} \mathrm{C}\right.$ Glass EGTs). Its $\mathrm{I}_{\mathrm{DS}}-\mathrm{V}_{\mathrm{GS}}$ characteristics highlight a considerable reduction in the anti-clockwise hysteresis. This fact is expected since the EC is burned-out, as already explained, so the ion trapping phenomena within the channel layer might be highly reduced. Moreover, a clear increase in both $\mathrm{I}_{\text {off }}$ and $\mathrm{I}_{\text {on }}$ of the device is visible from the same $\mathrm{I}_{\mathrm{DS}}-\mathrm{V}_{\mathrm{GS}}$ characteristics. This increase is related to an enhanced channel conductivity, resulting from the improved charge transport between the $\mathrm{ZnO}$ NPs due to the thermal degradation of EC. Again, the higher NP concentration in the $\mathrm{ZnO} 40$ ink in comparison with the $\mathrm{ZnO} 10$ one leads to a higher NP density in the printed films. Moreover, partial sintering of the NPs, during the burn-out process, should not be excluded, also in relation to the increasing $\mathrm{I}_{\mathrm{Off}}$ and $\mathrm{I}_{\mathrm{On}}$. In fact, it is known that the sintering temperatures of nanosized structures owing to the high surface-to-volume ratio are considerably lower compared to the bulk material [25]. As a result, the $\mathrm{ZnO} 40_{350}{ }^{\circ} \mathrm{C}$ Glass $E G T$ stands out with a $\mu_{\text {Sat }}$ of $5.73 \mathrm{~cm}^{2}(\mathrm{Vs})^{-1}$, an $\mathrm{I}_{\mathrm{On}} / \mathrm{I}_{\text {Off }}$ ratio of almost four orders of magnitude, and reduced hysteresis, less than $1 \mathrm{~V}$. The performance of these devices compares well with reported values for nanoparticle-based EGTs. Bong et al. [26] reported on $\mathrm{ZnO}$ transistors annealed at $280^{\circ} \mathrm{C}$, using an ion-gel as electrolyte (drop-casted) with a $\mu_{\text {Sat }}$ of $12.1 \mathrm{~cm}^{2}(\mathrm{Vs})^{-1}$ and an $\mathrm{I}_{\mathrm{on}} / \mathrm{I}_{\text {off }}$ ratio of about $10^{5}$. Santos et al. [11] have reported spin-coated gallium-indium-zinc-oxide (GIZO) NP EGTs, with $\mathrm{I}_{\text {on }} / \mathrm{I}_{\text {off }}$ ratios between $10^{3}$ and $10^{6}$ and a $\mu_{\text {Sat }}$ between $6 \times 10^{-3}$ and $1 \mathrm{~cm}^{2}$ $(\mathrm{Vs})^{-1}$. Likewise, Dasgupta et al. [15] have reported inkjet printed indium-tin-oxide (ITO) EGTs, with an $\mathrm{I}_{\mathrm{on}} / \mathrm{I}_{\text {off }}$ ratio of about $10^{4}$ and a mobility of $5 \mathrm{~cm}^{2}(\mathrm{Vs})^{-1}$, after annealing at $400{ }^{\circ} \mathrm{C}$.

It is worth mentioning that the $\mu_{\text {Sat }}$ here obtained for the fully printed ZnO EGTs may be influenced by surface roughness. Consequently, it generates charge traps at the $\mathrm{ZnO} /$ electrolyte as well as increases the contact resistance at S/D electrodes, as suggested by Dasgupta et al. [15].

Finally, we could reproduce our ZnO40 EGTs on conventional printing paper $\left(\mathrm{ZnO} 40_{150}{ }^{\circ} \mathrm{CPP}\right.$ EGT, Figure $3 \mathrm{c}, \mathrm{e})$ and MFC Kraft substrates $\left(\mathrm{ZnO}^{\circ} 0_{150}{ }^{\circ} \mathrm{C} \mathrm{MK}\right.$, Figure $\left.3 \mathrm{c}, \mathrm{f}\right)$, since they can withstand temperatures up to $150{ }^{\circ} \mathrm{C}$. The difference in the $\mu_{\text {Sat }},\left(0.01\right.$ and $\left.0.07 \mathrm{~cm}^{2}(\mathrm{Vs})^{-1}\right)$ for both paper substrates, depicted in Table 1, can be explained by the influence of the paper substrates roughness. Via 3D profilometry (see Figure S8), the scanned area $(500 \mu \mathrm{m} \times 500 \mu \mathrm{m})$ of the conventional printing paper and MFC Kraft yields an average surface roughness of 2.98 and $1.70 \mu \mathrm{m}$, respectively. As verified earlier, the high surface roughness of the substrate owing to the poor dispersion of the ZnO NPs 
contributes to a large interface roughness between the EGT channel and the CSPE. This result confirms conclusions drawn by Dasgupta et al. [15]. Consequently, the ineffective gating leads to non-uniform electric fields in the semiconducting layer, originating lower $\mu_{\text {Sat }}$. Moreover, increased S/D contact resistance can also affect the measured transfer characteristics and consequently the calculated carrier mobility.

Table 1. Summary of the electrical characterization of the produced fully printed ZnO NP EGTs: channel width and length ratio $(\mathrm{W} / \mathrm{L})$, the drain voltage $\left(\mathrm{V}_{\mathrm{DS}}\right)$, the turn on voltage $\left(\mathrm{V}_{\mathrm{on}}\right)$, the on-off current ratio $\left(\mathrm{I}_{\mathrm{on}} / \mathrm{I}_{\mathrm{off}}\right)$, the subthreshold swing $(\mathrm{SS})$, the transconductance $(\mathrm{gm})$, and the saturation mobility $\left(\mu_{\text {Sat }}\right)$.

\begin{tabular}{|c|c|c|c|c|c|c|c|}
\hline Device Designation & W/L & $\begin{array}{l}V_{\text {DS }} \\
\text { (V) }\end{array}$ & $\begin{array}{l}V_{\text {on }} \\
\text { (V) }\end{array}$ & $\mathrm{I}_{\mathrm{on}} / \mathrm{I}_{\text {off }}$ & $\begin{array}{c}\mathrm{SS} \\
\left(\mathrm{V} \mathrm{\textrm {dec } ^ { - 1 }}\right)\end{array}$ & $\begin{array}{l}\mathrm{g}_{\mathrm{m}} \\
\text { (S) }\end{array}$ & $\begin{array}{c}\mu_{\text {Sat }} \\
\left(\mathrm{cm}^{2}(\mathrm{Vs})^{-1}\right)\end{array}$ \\
\hline $\mathrm{ZnO}{ }_{350^{\circ} \mathrm{CG}} \mathrm{EGT}$ & 120 & 1.2 & 1.50 & $2.00 \times 10^{3}$ & 0.08 & $2.58 \times 10^{-6}$ & 0.02 \\
\hline $\mathrm{ZnO} 40150^{\circ} \mathrm{C} G \mathrm{EGT}$ & 120 & 1.1 & 2.20 & $1.55 \times 10^{3}$ & 0.11 & $3.55 \times 10^{-6}$ & 0.02 \\
\hline $\mathrm{ZnO} 40_{350}^{\circ} \mathrm{C}$ G EGT & 120 & 0.9 & 0.90 & $8.74 \times 10^{3}$ & 0.06 & $8.44 \times 10^{-4}$ & 5.73 \\
\hline $\mathrm{ZnO} 40_{150}^{\circ} \mathrm{Cpp}$ EGT & 120 & 1.0 & 2.10 & $1.73 \times 10^{3}$ & 0.01 & $1.41 \times 10^{-6}$ & 0.01 \\
\hline $\mathrm{ZnO} 40_{150}{ }^{\circ} \mathrm{C}$ MK EGT & 120 & 1.3 & 1.90 & $3.72 \times 10^{3}$ & 0.21 & $1.08 \times 10^{-5}$ & 0.07 \\
\hline
\end{tabular}

All the ZnO NP EGTs reported here exhibit extremely low subthreshold slope (SS), showing the rapidness of the ion accumulation process. Additionally, the characteristic low-voltage operation between -2 and $4 \mathrm{~V}$, for this device technology (EGTs), was confirmed. Besides that, the dynamic characterization of the $\mathrm{ZnO} 40_{150}{ }^{\circ} \mathrm{C}$ MK EGT (see Figure S9) showed that the device operates between 0.01 and $10 \mathrm{~Hz}$ without reaching the cut-off, in accordance with the capacitance/frequency dependence, keeping still above one order of magnitude in the $\mathrm{I}_{\mathrm{on}} / \mathrm{I}_{\text {off }}$ ratio.

\section{Conclusions}

In summary, this study reports a fully printed and flexible inorganic EGT on paper. Besides the low operation voltages, the devices have n-type behavior with an SS of $0.21 \mathrm{~V} \mathrm{dec}{ }^{-1}$, a $\mu_{\text {Sat }}$ of $0.07 \mathrm{~cm}^{2} \mathrm{~V}^{-1} \mathrm{~s}^{-1}$, and an $\mathrm{I}_{\mathrm{on}} / \mathrm{I}_{\text {off }}$ ratio of $3.72 \times 10^{3}$. Investigation in this field could lead to the effective roll-to-roll fabrication of printed logic circuits, with great implications for industrial printing standards, including sustainable and eco-friendly ink formulation. In this context, electrolyte gating, using printable electrolytes, is crucial for the development of printed transistors. In the near future, we foresee printed EGTs to be omnipresent in a wide range of applications, reaching from biosensors, smart packaging to wearable electronics all based on an ultra-low-cost and disposable/recyclable platforms.

Supplementary Materials: The following are available online at http:/ /www.mdpi.com/2079-4991/9/2/169/s1, Figure S1: AFM topographic images (without being annealed) of a) screen-printed ZnO10 ink and b) screen-printed $\mathrm{ZnO} 40$, Figure S2: Dependence of the resistance on the number of bending cycles, for screen-printed $\mathrm{ZnO} 40$ films on paper, Figure S3: Cross section image of the $\mathrm{ZnO} 40$ screen-printed film on paper, after being subjected to 1000 bending cycles. The cross section was prepared by FIB, Figure S4: Young's Modulus and Hardness results obtained for 3 different regions, for screen-printed $\mathrm{ZnO} 40$ films on paper after being subjected to the bending cycles, Figure S5: (a) Schematic representation of the electrochemical cell setup with an area (A) of $1.04 \mathrm{~cm}^{2}$ and (b) the corresponding ECM suggested by Dasgupta et al. adapted from [15] where $R_{\text {ext }}$ is contact resistance, $R_{b}$ and $\mathrm{C}_{\mathrm{b}}$ corresponds to the electrolyte resistance and capacitance, respectively, and CPE the constant phase element, and (c) the AFM topographic image of the screen-printed composite solid polymer electrolyte (CSPE), Figure S6: DSC-TG curves performed in air up to $500{ }^{\circ} \mathrm{C}$ for the Ethyl Cellulose (EC) powder, Figure S7: DSC-TG curves performed in air up to $500{ }^{\circ} \mathrm{C}$ for the binder solution (ethyl cellulose $5 \mathrm{wt} \%$ dissolved in a solvent mixture of toluene:ethanol (80:20 \%v/v), Figure S8: The 3D profilometry scan of the surface of the (a) printing paper and (b) MFC kraft substrates, Figure S9: Dynamic electrical characterization of the ZnO40 $150{ }^{\circ} \mathrm{C}$ MK EGT: variation of the $\mathrm{I}_{\mathrm{On}} / \mathrm{I}_{\mathrm{Off}}$ using a square-shaped $\mathrm{V}_{\mathrm{G}}\left(\mathrm{V}_{\mathrm{DS}}=1.3 \mathrm{~V}, 5\right.$ cycles for each frequency $\left.0.01,0.1,0.25,0.5 \mathrm{and} 1 \mathrm{~Hz}\right)$.

Author Contributions: J.T.C. performed most of the laboratory work, methodology, data analysis, and writing - original draft preparation. V.D. conducted the bending tests. P.G. and I.C. performed the printing processes and electrolyte preparation. E.F. and R.M. participated in funding acquisition and reviewed and edited the paper. A.C. and E.Z. performed the mechanical characterizations, electron microscopy, and formal analysis, 
and they reviewed and edited the paper. L.P. is credited for conceptualization, methodology, data analysis, supervision, and funding acquisitions and reviewed and edited the paper.

Funding: This research was funded by FCT_-Portuguese Foundation for Science and Technology-through the Ph.D. scholarships SFRH/BD/139225/2018 (José Tiago Carvalho), SFRH/BD/125191/2016 (Paul Grey), and SFRH/BD/126409/2016 (Inês Cunha). The authors would like to acknowledge the European Commission under project NewFun (ERC-StG-2014, GA 640598) and BET-EU (H2020-TWINN-2015, GA 692373). This work was also supported by the FEDER funds through the COMPETE 2020 Program and the National Funds through the FCT under the Project No. POCI-01-0145-FEDER-007688, Reference UID/CTM/50025, project PapEl, reference PTDC/CTM-NAN/5172/2014.

Acknowledgments: The authors would like to acknowledge Martin Gall for the supervision of Viorel Dubceac while at FhG-IKTS, to Daniela Gomes for some of the SEM images and to Ana Pimentel for the DSC-TG analysis.

Conflicts of Interest: The authors declare no conflict of interest.

\section{References}

1. Khan, S.; Lorenzelli, L.; Dahiya, R.; Member, S. Technologies for Printing Sensors and Electronics over Large Flexible Substrates: A Review. IEEE Sens. J. 2015, 15, 3164-3185. [CrossRef]

2. Kim, S.H.; Hong, K.; Xie, W.; Lee, K.H.; Zhang, S.; Lodge, T.P.; Frisbie, C.D. Electrolyte-Gated Transistors for Organic and Printed Electronics. Adv. Mater. 2013, 25, 1837. [CrossRef]

3. Herlogsson, L. Electrolyte-Gated Organic Thin-Film Transistors. Ph.D Dissertation, Linköping Universitet Institute of Technology, Linköping, Sweden, 2011.

4. Tate, J.; Rogers, J.A.; Jones, C.D.W.; Vyas, B.; Murphy, D.W.; Li, W.; Bao, Z.; Slusher, R.E.; Dodabalapur, A.; Katz, H.E. Anodization and Microcontact Printing on Electroless Silver: Solution-Based Fabrication Procedures for Low-Voltage Electronic Systems with Organic Active Components. Langmuir 2000, 16, 6054-6060. [CrossRef]

5. Inoue, Y. Organic thin-film transistors based on anthracene oligomers. J. Appl. Phys. 2004, 95, 5795-5799. [CrossRef]

6. Yu, X.J.; Xu, J.B.; Cheung, W.Y.; Ke, N. Optimizing the growth of vanadyl-phthalocyanine thin films for high-mobility organic thin-film transistors. J. Appl. Phys. 2007, 102. [CrossRef]

7. Hong, K.; Kim, S.H.; Lee, K.H.; Frisbie, C.D. Printed, sub-2V ZnO Electrolyte Gated Transistors and Inverters on Plastic. Adv. Mater. 2013, 25, 3413-3418. [CrossRef] [PubMed]

8. Park, S.; Lee, S.; Kim, C.-H.; Lee, I.; Lee, W.-J.; Kim, S.; Lee, B.-G.; Jang, J.-H.; Yoon, M.-H. Sub-0.5 V Highly Stable Aqueous Salt Gated Metal Oxide Electronics. Sci. Rep. 2015, 5, 13088. [CrossRef] [PubMed]

9. Bandiello, E.; Sessolo, M.; Bolink, H.J. Aqueous electrolyte-gated $\mathrm{ZnO}$ transistors for environmental and biological sensing. J. Mater. Chem. C 2014, 2, 10277-10281. [CrossRef]

10. Wang, D.; Noël, V.; Piro, B. Electrolytic Gated Organic Field-Effect Transistors for Application in Biosensors-A Review. Electronics 2016, 5, 9. [CrossRef]

11. Santos, L.; Nunes, D.; Calmeiro, T.; Branquinho, R.; Salgueiro, D.; Barquinha, P.; Pereira, L.; Martins, R.; Fortunato, E. Solvothermal Synthesis of Gallium-Indium-Zinc-Oxide Nanoparticles for Electrolyte-Gated Transistors. ACS Appl. Mater. Interfaces 2015, 7, 638-646. [CrossRef]

12. Barquinha, P.; Pereira, S.; Pereira, L.; Wojcik, P.; Grey, P.; Martins, R.; Fortunato, E. Flexible and Transparent $\mathrm{WO}_{3}$ Transistor with Electrical and Optical Modulation. Adv. Electron. Mater. 2015, 1, 1500030. [CrossRef]

13. Rose, A. Considerations in Formulation and Manufacturing of Thick Film Inks. Electrocompon. Sci. Technol. 1981, 9, 43-49. [CrossRef]

14. Inukai, K.; Takahashi, Y.; Ri, K.; Shin, W. Rheological analysis of ceramic pastes with ethyl cellulose for screen-printing. Ceram. Int. 2015, 41, 5959-5966. [CrossRef]

15. Dasgupta, S.; Stoesser, G.; Schweikert, N.; Hahn, R.; Dehm, S.; Kruk, R.; Hahn, H. Printed and Electrochemically Gated, High-Mobility, Inorganic Oxide Nanoparticle FETs and Their Suitability for High-Frequency Applications. Adv. Funct. Mater. 2012, 22, 4909-4919. [CrossRef]

16. Antunes, J.M.; Fernandes, J.V.; Sakharova, N.; Oliveira, M.C.; Menezes, L.F. On the determination of the Young's modulus of thin films using indentation tests. Int. J. Solids Struct. 2007, 44, 8313-8334. [CrossRef]

17. Yuan, H.; Shimotani, H.; Ye, J.; Yoon, S.; Aliah, H.; Tsukazaki, A.; Kawasaki, M.; Iwasa, Y. Electrostatic and Electrochemical Nature of Liquid-Gated Electric-Double-Layer Transistors Based on Oxide Semiconductors. J. Am. Chem. Soc. 2010, 132, 18402-18407. [CrossRef] 
18. Jović, V.D.; Jović, B.M. EIS and differential capacitance measurements onto single crystal faces in different solutions: Part I: $\operatorname{Ag}(111)$ in $0.01 \mathrm{M} \mathrm{NaCl}$. J. Electroanal. Chem. 2003, 541,1-11. [CrossRef]

19. Nasr, B.; Wang, D.; Kruk, R.; Rösner, H.; Hahn, H.; Dasgupta, S. High-Speed, Low-Voltage, and Environmentally Stable Operation of Electrochemically Gated Zinc Oxide Nanowire Field-Effect Transistors. Adv. Funct. Mater. 2013, 23, 1750-1758. [CrossRef]

20. Fortunato, E.; Correia, N.; Barquinha, P.; Pereira, L.; Goncalves, G.; Martins, R. High-Performance Flexible Hybrid Field-Effect Transistors Based on Cellulose Fiber Paper. IEEE Electron Device Lett. 2008, 29, 988-990. [CrossRef]

21. Pereira, L.; Gaspar, D.; Guerin, D.; Delattre, A.; Fortunato, E.; Martins, R. The influence of fibril composition and dimension on the performance of paper gated oxide transistors. Nanotechnology 2014, 25, 094007. [CrossRef]

22. Gaspar, D.; Fernandes, S.N.; de Oliveira, A.G.; Fernandes, J.G.; Grey, P.; Pontes, R.V.; Pereira, L.; Martins, R.; Godinho, M.H.; Fortunato, E. Nanocrystalline cellulose applied simultaneously as the gate dielectric and the substrate in flexible field effect transistors. Nanotechnology 2014, 25, 094008. [CrossRef] [PubMed]

23. Grey, P.; Gaspar, D.; Cunha, I.; Barras, R.; Carvalho, J.T.; Ribas, J.R.; Fortunato, E.; Martins, R.; Pereira, L. Handwritten Oxide Electronics on Paper. Adv. Mater. Technol. 2017, 2, 1700009. [CrossRef]

24. Cunha, I.; Barras, R.; Grey, P.; Gaspar, D.; Fortunato, E.; Martins, R.; Pereira, L. Reusable Cellulose-Based Hydrogel Sticker Film Applied as Gate Dielectric in Paper Electrolyte-Gated Transistors. Adv. Funct. Mater. 2017, 27, 1606755. [CrossRef]

25. Kamyshny, A.; Magdassi, S. Conductive Nanomaterials for Printed Electronics. Small 2014, 10, $3515-3535$. [CrossRef]

26. Bong, H.; Lee, W.H.; Lee, D.Y.; Kim, B.J.; Cho, J.H.; Cho, K. High-mobility low-temperature ZnO transistors with low-voltage operation. Appl. Phys. Lett. 2010, 96, 2008-2011. [CrossRef]

(C) 2019 by the authors. Licensee MDPI, Basel, Switzerland. This article is an open access article distributed under the terms and conditions of the Creative Commons Attribution (CC BY) license (http://creativecommons.org/licenses/by/4.0/). 